\title{
Phenomenological Profiles of Autobiographical Memories in Individuals with Depression
}

\author{
María Lolich ${ }^{1}$ \\ Research Institute, School of Psychology, University of Buenos Aires, \\ Buenos Aires, Argentina \\ Research Center in Neuroscience and Clinical Neuropsychology, School of Social Sciences, \\ University of Palermo, Buenos Aires, Argentina \\ Susana Azzollini \\ Research Institute, School of Psychology, University of Buenos Aires, \\ Buenos Aires, Argentina \\ Center for Social and Human Research for Defense, National Military College, \\ Higher Education Army, Institute Ministry of Defense, Buenos Aires, Argentina \\ Gustavo Vázquez \\ Research Center in Neuroscience and Clinical Neuropsychology, School of Social Sciences, \\ University of Palermo, Buenos Aires, Argentina
}

\begin{abstract}
Autobiographical memories are deeply linked with emotional regulation processes and self-concept. Conversely, in case of affective disorders, the access to specific phenomenological components would be impaired. Intentional non-probabilistic sampling was carried out, involving 94 individuals with major depression and 188 healthy individuals in the city of Buenos Aires, Argentina. The phenomenological components of significant autobiographical recollections were contrasted, considering their quantity and intensity. In addition, the depressive individuals' performances were compared according to the presence or absence of previous depressive episodes, psychopharmacological treatment and severity of symptoms. Statistically significant differences were found in the total amount and intensity of the recalled phenomenological components, in which the clinical group presented reduced memory $(p<$ .001). Besides, the dimensions: Valence, Visual Imagery, Sensoriality, Inter-subjectivity and Clarity also presented significant differences. Notwithstanding, non-significant differences were observed during the secondary analysis in relation to the clinical variables. Individuals with depression showed a distinctive phenomenological memory pattern in comparison to controls. Considering phenomenological memory modalities in the light of cognitive models of Mindfulness and Imagery entails relevant clinical implications.
\end{abstract}

Keywords: Autobiographical memory, specificity, experience, depression.

Mailing address: 1612 1B (CP: 1425), Buenos Aires, Argentina. Phone: +541148273951. E-mail: mlolic@ palermo.edu

Study developed in the research project entitled "Phenomenological dimensions in the recall of significant autobiographical memories" in the context of a National Scientific and Technical Research Council (CONICET) doctoral fellowship granted to Maria Lolich. 


\section{Perfis Fenomenológicos da Evocação Autobiográfica em Indivíduos com Depressão}

\section{Resumo}

Os registos autobiográficos encontram-se em relação íntima com os procesoss de regulação emocional e com a concepção de si mesmo. Por outro lado, os procesos de acesso aos componentes fenomenológicos específicos estariam alterados durante a ocorrência de alterações afetivas. A amostra não probabilística intencional foi constituída por 94 indivíduos com depressão maior e 188 indivíduos sãos, provenientes da cidade de Buenos Aires, Argentina. Foram comparados os componentes fenomenológicos das memorias autobiográficas significativas quanto à sua quantidade e intensidade. Ao mesmo tempo, comparou-se o rendimento do grupo depressivo de acordo com a presença ou ausência de episódios depressivos prévios, tratamento psicofarmacológico e severidade dos sintomas. Encontraram-se diferenças significativas na Quantidade e Intensidade Totais dos componentes fenomenológicos evocados, apresentando o grupo clínico uma evocação reduzida $(p<0,001)$. Ao mesmo tempo, as dimensões Valencia, Imagem Visual, Sensorialidade, Intersubjetividade e Claridade também apresentaram diferenças significativas. Contudo, não se encontraram diferenças significativas ao realizar as análises secundárias de acordo com as variáveis clínicas. Os individuos com depressão mostraram um padrão distintivo de evocação fenomenológica de suas memórias em comparação com os controles. Considerar as modalidades fenomenológicas de evocação autobiográfica à luz dos modelos cognitivos em Mindfulness e Imagem tem implicações clínicas relevantes.

Palavras-chave: Memória autobiográfica, especificidade, experiencia, depressão.

\section{Perfiles Fenomenológicos de Evocación Autobiográfica en Individuos con Depresión}

\section{Resumen}

Los recuerdos autobiográficos se encuentran en íntima relación con los procesos de regulación emocional y con la concepción del sí mismo. Por otro lado, el acceso a los componentes fenomenológicos específicos se vería disminuido de ocurrir alteraciones afectivas. Se llevó a cabo un muestro no probabilístico intencional de 94 individuos con depresión mayor y de 188 individuos sanos de la ciudad de Buenos Aires, Argentina. Fueron comparados los componentes fenomenológicos de los recuerdos autobiográficos significativos en cuanto a su cantidad e intensidad. Asimismo, se comparó el rendimiento dentro del grupo depresivo, de acuerdo a la presencia o ausencia de episodios depresivos previos, tratamiento psicofarmacológico y severidad sintomatológica. Se encontraron diferencias significativas en la Cantidad e Intensidad Total de los componentes fenomenológicos evocados, presentando el grupo clínico una evocación reducida $(p<.001)$. Las dimensiones Valencia, Imaginería Visual, Sensorialidad, Intersubjetividad y Claridad también presentaron diferencias significativas. No se encontraron diferencias al realizar los análisis secundarios de acuerdo a las variables clínicas. Los individuos con depresión manifestaron un patrón distintivo de evocación fenomenológica de sus recuerdos en comparación a individuos sanos. Considerar las modalidades fenomenológicas de evocación autobiográfica a la luz de los modelos cognitivos en Mindfulness e Imaginería posee implicancias clínicas de relevancia.

Palabras clave: Memoria autobiográfica, especificidad, experiencia, depresión.

Significant life experiences tend to be preserved in the form of autobiographical recollections (ARs). These representations, differently from what happens with the engrams of semantic memory, can contain a wide range of phenomenological components. Thus, when people 
evoke ARs, they recreate past experiences in the present with a high level of specificity and detail (Magila \& Xavier, 2000; Sutin \& Robins, 2007; Tulving, 2002).

Based on a series of autobiographical memory (AM) studies using different methods, various phenomenological dimensions were delimited, characteristic of the ARs (Lolich \& Azzollini, 2012; Luchetti \& Sutin, 2015; Sutin \& Robins, 2007). One of the main constructs remits to the visual imagery and visual perspective of evocation (Greenberg \& Knowlton, 2014; Sutin \& Robins, 2010). In addition, the remaining sensory components, valence and affective intensity and the feeling of time travelling tend to be present (Bluck, Alea, \& Habermas, 2005; Sutin \& Robins, 2007; Tulving, 2002).

In recent years, there has been growing interest in delimiting the phenomenological profiles in the recall of significant ARs. Studies in the United States and Europe have found significant associations between the type of phenomenological dimensions evoked and other psychological and psychopathological variables (Janssen, Kristo, Rouw, \& Murre, 2015; Montebarocci, Luchetti, \& Sutin, 2014). Thus, it has been demonstrated that individuals with major depressive disorder (MDD) recall their ARs in an overgeneralized way in comparison with healthy individuals (King et al., 2010). That is, this clinical population tends to evoke its ARs in a diffuse manner, in which similar events tend to fuse in a common mnemonic category and the delimitation of concrete details is scarce (Williams et al., 2007). In particular, people with MDD predominantly evoke their ARs from a visual, observing perspective and present reduced autonoetic consciousness (Bergouignan et al., 2008; Lemogne et al., 2006). Despite the trend to consider that this clinical group evokes recollections structured on a negative type of valence (Park, Goodyer, \& Teasdale, 2002; Watkins \& Teasdale, 2004), that does not seem to be the result in all studies and, in exchange, low affective intensity is evidenced as a characteristic trait (Kuyken \& Howell, 2006; Werner-Seidler \& Moulds, 2011a).
With regard to the above, cognitive psychology models [Mindfulness (Williams, Teasdale, Segal, \& Soulsby, 2000) and Imagery (Holmes \& Mathews, 2010)] highlight MDD patients' trend to overgeneralize. They sustain that an overgeneralized cognitive style of information processing is particularly counterproductive. Although recalling ARs in general would avoid direct contact with experiences that might be painful, these emotional implications would implicitly continue acting and would favor the establishment of biased cognitions (Dinis, Carvalho, Gouveia, \& Estanqueiro, 2015; Williams et al., 2007). If the event preserved its impact in the self but specific access to its phenomenological details is not possible, it would not be appropriately integrated into the corresponding memory networks (Sumner, Griffith, \& Mineka, 2010; Williams et al., 2007). This memory, generalized in the details but high in terms of affective repercussions in the medium term, would enhance people's vulnerability to intrusive recollections and dysfunctional cognitions (Bessell, Watkins, \& Williams, 2008; Sumner et al., 2014). Thus, difficulties to get specific contact with the experience, like in the case of significant ARs, is associated with a worse prognosis and even with a greater probability of relapse (Crawley, 2014; Kuyken \& Dalgleish, 2011; Sumner et al., 2010).

In this sense, the direct relation between the number of major depressive episodes and memory deterioration in individuals with MDD has been reported (MacQueen, Galway, Hay, Young, \& Joffe, 2002). Therefore, it is important to act early in the attempt to reduce the chances of new episodes. Another clinical variable of interest is the severity of depressive symptoms. Different studies (King et al., 2010; Liu, Li, Xiao, Yang, \& Jiang, 2013) postulate that, after MDD has been triggered, the influence on memory is independent from the clinical severity of the episode. More than the affective state, the dysfunctional modality of cognitive processing would be responsible for the biases in AM. Finally, another aspect of interest relates to the effect of psychotropic drugs on AM tasks (King et al., 2010). Although some authors (Zoladz, 
Park, Muñoz, Fleshner, \& Diamond, 2008) suggest that antidepressant drugs could actually present neuroprotective and even neurotrophic events, reducing the cognitive deficits (for a review see Tanis, Newton, \& Duman, 2007), other researchers report poor memory responses associated with the use of psychopharmacological medication in patients with MDD (Brittlebank, Scott, Williams, \& Ferrier, 1993).

Knowledge on the phenomenological recall styles of significant ARs in individuals with depressive disorders would be of great clinical and theoretical applicability. Being able to identify the phenomenological dimensions with a higher degree of overgeneralization and what clinical variables are related to a better or worse performance would provide very relevant information: To give an example, these data would be useful in designing and applying psychotherapeutic interventions to work with significant episodes in the patients' life. Specifically favoring the recall of ARs in clinical consulting services can entail significant therapeutic benefits. Having concrete access to negative recollections permits a better processing of the facts, while specifically recalling positive recollections grants emotional benefits (Bessell et al., 2008; Werner-Seidler $\&$ Moulds, 2011b). Nevertheless, no studies are available involving Latin American populations that have attempted to identify the characteristic phenomenological profiles in the recall of significant ARs in MDD patients. On the other hand, on few occasions have psychometrically valid and reliable techniques been used in studies (Rottenberg, Joormann, Brozovich, \& Gotlib, 2005; Sutin \& Robins, 2007).

The primary objective in this research is to compare the phenomenological profiles in the recall of significant ARs according to adult individuals with and without MDD in the city of Buenos Aires (Argentina). The specific goal is to assess statistically significant differences between the groups in the quantity and intensity of phenomenological components recalled. The secondary objectives are to assess statistically significant differences in the total quantity and intensity of phenomenological components in the group of MDD patients according to the presence or absence of previous depressive episodes, psychopharmacological treatment in course and severity of depressive symptoms.

The main hypothesis, respectively, is that the phenomenological profile in MDD patients' recall of significant ARs reveals significant differences when compared to the phenomenological memory profile of individuals without MDD. When compared to people without MDD, individuals with MDD recall fewer phenomenological components of significant ARs and the intensity of their recollection is lower. The secondary hypotheses raised is that individuals with MDD and previous depressive episodes, as well as MDD patients in psychopharmacological treatment, evoke the phenomenological components present in their ARs to a lesser extent and intensity when compared to individuals with MDD without previous depressive episodes and without ongoing psychopharmacological treatment. In addition, individuals currently experiencing more severe symptoms recall the phenomenological components to a lesser extent and intensity when compared to individuals with MDD with milder depressive symptoms.

\section{Methods}

\section{Study Design}

An observational, descriptive and cross-sectional correlation study was undertaken.

\section{Participants}

A non-probabilistic intentional sample of 282 adults (see Table 1) with MDD $\left(n_{\mathrm{MDD}}=94\right)$ and without MDD $\left(n_{\text {CONTR }}=188\right)$ was taken, living in the Autonomous City of Buenos Aires (Argentina).

The clinical group included individuals between 18 and 65 years of age with a primary diagnosis of MDD before the start of the study, who scored $\geq 13$ on the Beck Depression Inventory (BDI) and who accepted to participate by signing the informed consent form. The control group included individuals who scored $<13$ on the BDI, indicated no antecedents of psychological or psychiatric treatment due to 
Table 1

Sociodemographic and Clinical Characteristics of the Sample

\begin{tabular}{lcccc}
\hline & Total Sample & MDD group & Control group & $p$-value \\
\hline Cases $[n(\%)]$ & $282(100)$ & $94(33.3)$ & $188(66.7)$ & \\
Age [years, median $\left.\left(\mathrm{IR}^{*}\right)\right]$ & $31(29)$ & $32(29)$ & $30.5(28.7)$ & $.833^{\text {a }}$ \\
Women $[n(\%)]$ & $168(59.6)$ & $56(59.6)$ & $112(59.6)$ & $1.000^{\mathrm{b}}$ \\
Marital status $[(n(\%)]$ & & & & \\
$\quad$ Single & $132(46.8)$ & $45(47.9)$ & $87(46.3)$ & $.740^{\mathrm{b}}$ \\
$\quad$ With partner & $86(30.5)$ & $26(27.6)$ & $60(31.9)$ & \\
$\quad$ Divorced & $64(22.7)$ & $23(24.5)$ & $41(21.8)$ & \\
Education level $[n(\%)]$ & & & & \\
$\quad$ Unfinished secondary & $34(12.1)$ & $13(13.8)$ & $21(11.2)$ & \\
Finished secondary & $38(13.5)$ & $12(12.8)$ & $26(13.8)$ & \\
$\quad$ Unfinished higher & $166(58.9)$ & $57(60.6)$ & $109(58)$ & $.748^{\mathrm{b}}$ \\
$\quad$ Finished higher & $44(15.6)$ & $12(12.8)$ & $32(17)$ & \\
Clinical characteristics & & & & \\
Total BDI score [median (IR)] & $6(12)$ & $18(13)$ & $3(5)$ & \\
$\quad$ Without significant symptoms & $188(100)$ & $0(0)$ & $188(100)$ & \\
Mild depressive episode & $38(13.5)$ & $38(40.4)$ & $0(0)$ & \\
Moderate depressive episode & $41(14.5)$ & $41(43.6)$ & $0(0)$ & $.001^{\mathrm{b}}$ \\
Severe depressive episode & $15(5.3)$ & $15(16)$ & $0(0)$ & \\
Previous depressive episodes $[n(\%)]$ & $54(19.1)$ & $54(57.44)$ & $0(0)$ & \\
Current psychopharmacological treatment $[n(\%)]$ & $61(21.6)$ & $61(64.89)$ & $0(0)$ & \\
\hline
\end{tabular}

Note. ${ }^{*} \mathrm{IR}=$ Interquartile Range.

${ }^{\mathrm{a}}$ Median Test. ${ }^{\mathrm{b}}$ Chi-Squared Test.

affective disorders and accepted to participate in the study by signing the informed consent form. For both groups, individuals with previous or current antecedents of personality disorder, acute stress disorder, posttraumatic stress disorder, obsessive-compulsive disorder, schizophrenias, substance-related disorders, organic mental disorders, mental delay, medical conditions that could affect cognitive performance and individuals unable to grant their voluntary consent were excluded. In addition, even when the participants complied with the inclusion criteria, individuals who wanted to drop out were excluded. Thus, $n_{\mathrm{MDD}}=2$ individuals with antecedents of psychiatric treatment due to schizophrenia, $n_{\mathrm{MDD}}=3$ and $n_{\text {CONTR }}=6$ individuals were excluded due to antecedents of relevant medical conditions.

Using the pairing technique (Hernández Sampieri, Fernández Collado, \& Baptista, 2006), in the constitution of the group without MDD, the variables age, sex and education level of each case included in the group with MDD were paired. In that sense, as presented in Table 1, the statistical comparison of the sociodemographic variables between both groups was not significant. The statistical tests for the measuring and distribution of the variables were undertaken. All tests were two-tailed, with significance $p<.05$.

Calculation of Sample Size. Based on a pilot study of 15 individuals in each group, information was collected on the means, variances and 
approximate total scores. Next, the sample size for comparison of means was calculated. Considering $80 \%$ power, $95 \%$ confidence level, 222 variance for the control group, a significant minimum difference of four points between the groups for the primary results of the Assessment Scale of Significant Autobiographical Recollections [Escala de Evaluación de Recuerdos Autobiográficos Significativos (EERAS)] and applying a two-tailed test, using the software Piface (Lenth, 2006-2009), a total $n$ per group of 188 individuals was estimated. In view of the difficulties to gather this number of individuals in the clinical group, in the end, the size of the group with MDD was estimated at 94 participants, against 188 for the group without MDD. Nevertheless, as the clinical group was smaller, this would reduce the statistical power because, if significant statistical differences were detected between the groups, the evidence in favor of these differences would be larger (Camacho Sandoval, 2008).

\section{Tools}

The variables history of previous depressive episodes and presence of ongoing psychopharmacological treatment were collected from the patients' clinical histories.

Beck Depression Inventory (BDI). To assess the severity of depressive symptoms, the translated version of the BDI adapted to and standardized for the Argentinean population was used (Beck, Steer, Ball, \& Ranieri, 1996; Bonicatto, Dew, \& Soria, 1998; Lasa, Ayuso-Mateos, Vázquez-Barquero, Díez-Manrique, \& Dowrick, 2000). The BDI is a self-administered tool that includes 21 items of depressive symptoms; each item includes four alternative answers, corresponding to a score from zero to three according to the severity of the symptom (maximum score 63). To obtain the final score, the scores corresponding to each item are added up. The local adaptation of the tool possesses satisfactory psychometric properties - including a 100\% sensitivity and 99\% specificity, with an estimated predictive power of $72 \%$ (Bonicatto et al., 1998).

The cut-off score used - 13 or superior was employed in earlier epidemiological studies
(Lasa et al., 2000; Leiderman, Vázquez, Lolich, $\&$ Baldessarini, 2012). The total score can be classified as follows: 0-12 (absence of significant depressive symptoms); 13-16 (mild depression); 17-29 (moderate depression); 30-63 (severe depression; Bonicatto et al., 1998; Leiderman et al., 2012).

Assessment Scale of Significant Autobiographical Recollections (EERAS). To assess the phenomenological recollection profile in individuals with and without MDD, the EERAS was used (validated by Lolich \& Azzollini, 2016). This scale has been designed to assess the phenomenological recollection profiles of significant ARs. These consist of how many and how intensely the phenomenological components presented in the ARs are recalled.

The EERAS consists of 47 items: 30 Likert items grouped in eight dimensions (Visual Imagery, Valence, Impact in the self, Sensoriality, Clarity, Intersubjectivity, Distancing-Identification and Intensity), nine closed and eight open items. The tool presents satisfactory psychometric properties - internal consistency of 0.892 and total explained variance of $65.77 \%$. This results in two main scores related to the total number of phenomenological components and the total intensity of the recollection, as well as categorical information on the valence and affective intensity of the recollection. In addition, partial scores can be obtained for each of the phenomenological dimensions concerning intensity and quantity. As the objectives of this study were solely quantitative, in this paper, only the Likert-scale items were analyzed.

The initial instruction of the tool asks the participant to recollect a significant autobiographical memory that had lasted less than one day (Williams, 1995). This event should remit to a specific moment, that is, it should be related to a punctual fact in the participant's biography (Williams, 1995; Williams et al., 2007). The distinct items in the tool are presented as a series of assertions (i.e., "In the image displayed to me, I can distinguish some colors", "I recall one or more sounds") concerning which the participant is expected to indicate to what extent (s)he agrees or disagrees ("strongly disagrees"; "disagrees"; "I 
am not sure", "I agree" and "I strongly agree").

Number of components. The total score (and the partial score for each dimension) for the number of phenomenological components recalled results from the sum of the phenomenological components the participant has indicated as present in the memory of the recollection. One point is attributed to each "I agree" or "I strongly agree" answer for the distinct items in the eight dimensions of the EERAS. The final score is obtained through the sum of attributing one point to the presence and zero points to the absence of each item.

Recollection intensity. The total score (and the partial score for each dimension) for how intensely each phenomenological component is recalled results from the sum of each of the answers the participant has marked for each item in the scale. The maximum score is five points for "I strongly agree", against the minimum of one point for "I strongly disagree". The final score corresponds to the total sum of the scores for each of the answers the participant has given to each of the items.

\section{Procedure}

The participants were recruited through network sampling (Hernández Sampieri et al., 2006) in 2013-2014. A sociodemographic questionnaire, the EERAS and the BDI were administered to the groups with and without MDD.

The individuals with MDD were contacted at different health centers located in distinct communes of the Autonomous City of Buenos Aires (Argentina). All of them were outpatients due to MDD as the primary diagnosis, according to the Diagnostic and Statistical Manual for the Mental Health-Text Revision ([DSM-IVTR], $4^{\text {th }}$ ed., American Psychiatric Association [APA], 2000), and scored $\geq 13$ on the BDI. The health institutions approved a short version of the research protocol in the respective teaching and research committees and ethics committees. Then, the necessary approval was obtained from the central government committee of the City of Buenos Aires. The participants with MDD were referred by the professionals in charge of the treatment. The individuals without psychopathological antecedents were contacted through network sampling (Hernández Sampieri et al., 2006), with a view to pairing with the sociodemographic variables of the clinical group. Individuals were invited who lived in the same communes where the health institutions were located which the participants in the MDD group were recruited from.

Upon admission to the study, both groups signed the informed consent form, concerning the use of their data for the research. In this free and voluntary consent, the future anonymity of the information provided was guaranteed and, for the clinical sample, the absence of consequences for the care received. The tools were applied in a balanced manner (half of the sample in each group answered the BDI first, followed by the EERAS, and vice-versa).

\section{Data Analysis}

The data collected through the administration of the sociodemographic questionnaire, the BDI and the EERAS were analyzed statistically. After the data matrix was explored, descriptive and inferential analyses were applied, according to the measuring level of the variables. In view of the distribution of the variables and as the parametrical premises were not complied with, Mann-Whitney's non-parametric test was used for comparisons between both groups and Kruskal-Wallis test for comparisons between the three subgroups of individuals with MDD with distinct degrees of symptom severity. An error $\alpha \leq .05$ was accepted for the analysis of the primary objectives. For the secondary objectives, Bonferroni's correction was applied according to the number of multiple comparisons made $(\alpha / 6 \leq .0008)$. This was intended to control the type I error rate. In addition, for each of the comparisons made, the effect size was estimated for non-parametrical tests, using Rosenthal's $r$ coefficient (1991) with a 95\% confidence interval (Rosenthal, 1991; Téllez, García, \& Corral-Verdugo, 2015).

No case had to be excluded as all individuals answered at least $95 \%$ of the items (Carracedo-Martínez \& Figueiras, 2006). The software SPSS version 18 was used in Spanish. 


\section{Results}

\section{Exploration of Data Matrix}

In the initial exploration of the data, no atypical values were detected. None of the cases or items presented more than $5 \%$ of void answers. No statistically significant differences were detected (at $p>.05$ ) in the scores according to the application order of the tools in each group.

After the EERAS had been administered to the groups with and without MDD, the indices from the reliability analysis were superior to .80. On the other hand, the partial indices were also satisfactory (>.70). Internal consistency coefficients slightly inferior to the minimum values acceptable (Cortina, 1993; Cronbach, 1951) were only found in the dimensions
Affectivity $\quad(\mathrm{MDD}=0.651 ; \quad \mathrm{CONTR}=0.593)$, Intersubjectivity $(\mathrm{MDD}=0.538 ; \mathrm{CONTR}=0.590)$ and Sensoriality $(\mathrm{MDD}=0.620 ; \mathrm{CONTR}=0.660)$.

\section{Total Intensity and Quantity of Components in the Group with and without MDD}

Highly significant differences were found between the groups in the main EERAS scores. That was observed for the Total Quantity $(p<.001)$ and Total Intensity $(p<.001)$ of the referred phenomenological components. Individuals in the group with MDD recalled less phenomenological components of their significant ARs. The intensity of their recollection was also lower. Likewise, the estimated effect size for these analyses was moderate (see Table 2).

Table 2

EERAS Results in Group with and without MDD

\begin{tabular}{|c|c|c|c|c|}
\hline $\begin{array}{l}\text { EERAS } \\
\text { Dimensions }\end{array}$ & $\begin{array}{l}\text { Group with MDD } \\
\text { [median (IR)] }\end{array}$ & $\begin{array}{l}\text { Group without MDD } \\
\text { [median (IR)] }\end{array}$ & $p$-value ${ }^{\mathrm{a}}$ & $\begin{array}{l}\text { Estimated effect size } \\
\qquad\left[r^{b}(\mathrm{CI})\right]\end{array}$ \\
\hline \multicolumn{5}{|l|}{ Visual Imagery } \\
\hline Number of Components & $6(2.2)$ & $6(2)$ & $.033^{*}$ & $-0.127(-0.24 ;-0.01)$ \\
\hline Intensity of Components & $28(8)$ & $29(5)$ & .091 & $-0.100(-0.02 ; 0.01)$ \\
\hline \multicolumn{5}{|l|}{ Valence } \\
\hline Number of Components & $1(4)$ & $4(2)$ & $.001 * * *$ & $-0.363(-0.48 ;-0.25)$ \\
\hline Intensity of Components & $14(12)$ & $22(6)$ & $.001 * * *$ & $-0.396(-0.51 ;-0.28)$ \\
\hline \multicolumn{5}{|l|}{ Impact in the self } \\
\hline Number of Components & $4(1)$ & $3(3)$ & .470 & $-0.118(-0.24 ;-0.01)$ \\
\hline Intensity of Components & $17(4)$ & $16(7)$ & .380 & $-0.124(-0.02 ;-0.01)$ \\
\hline \multicolumn{5}{|l|}{ Sensoriality } \\
\hline Number of Components & $1(1.2)$ & $2(1.7)$ & .135 & $-0.089(-0.20 ; 0.02)$ \\
\hline Intensity of Components & $10(5.2)$ & $12(4.7)$ & $.024 *$ & $-0.134(-0.25 ;-0.01)$ \\
\hline \multicolumn{5}{|l|}{ Clarity } \\
\hline Number of Components & $3(1)$ & $3(0)$ & $.006 * *$ & $-0.165(-0.28 ;-0.04)$ \\
\hline Intensity of Components & $12(4)$ & $13(3)$ & $.031^{*}$ & $-0.129(-0.24 ;-0.01)$ \\
\hline \multicolumn{5}{|l|}{ Intersubjectivity } \\
\hline Number of Components & $2(1)$ & $3(1)$ & $.030^{*}$ & $-0.129(-0.25 ;-0.01)$ \\
\hline Intensity of Components & $12(4.2)$ & $12(4)$ & $.022^{*}$ & $-0.136(-0.25 ;-0.01)$ \\
\hline \multicolumn{5}{|l|}{ Distancing-Identification } \\
\hline Number of Components & $2(1)$ & $2(2)$ & .809 & $-0.014(-0.25 ;-0.01)$ \\
\hline Intensity of Components & $8(3.2)$ & $8(4)$ & .707 & $-0.001(-0.13 ;-0.10)$ \\
\hline \multicolumn{5}{|l|}{ Affectivity } \\
\hline Number of Components & $2(2)$ & $2(1)$ & .563 & $-0.022(-0.14 ; 0.09)$ \\
\hline Intensity of Components & $9(3)$ & $8(3)$ & .152 & $-0.034(-0.15 ; 0.08)$ \\
\hline Total Number of Components & $20(7.2)$ & $22(7.7)$ & $.001 * * *$ & $-0.208(-0.32 ;-0.09)$ \\
\hline Total Intensity of Components & $107.50(18.2)$ & $116.50(21.7)$ & $.001 * * *$ & $-0.239(-0.35 ;-0.12)$ \\
\hline
\end{tabular}

${ }^{a}$ Mann Whitney's $U$ test. ${ }^{\text {b }}$ Rosenthal's $r$ coefficient.

$* p<.05 ; * * p<.01 ; * * * p<.001$. 


\section{Quantity of Components per Dimension.} When comparing the number of phenomenological components recalled in each group for each of the eight phenomenological dimensions, significant differences were found (see Table 2).

When recalling the ARs, the individuals without MDD indicated a larger number of components in the following dimensions: Visual Imagery, Valence, Clarity and Intersubjectivity (Table 2). Thus, the dimension Valence revealed highly significant intergroup differences $(p<.001)$. Considering the way in which the items to assess this dimension are written, individuals in the control group (median $=4$; IR $=2$ ) had recollections of more positive emotional content than the clinical group (median $=1$; IR $=4$ ). In addition, the estimated effect size of this reported difference was moderate $[r=-0.363$ $(-0.44 ;-0.25)]$. On the other hand, concerning the number of components in the dimension Clarity, highly significant differences were also observed $(p=.006)$. Although the median score was the same in the clinical group (median $=3$; $\mathrm{IR}=1$ ) and in the reference group (median $=3$; $\mathrm{IR}=0$ ), the dispersion measure was higher in the clinical group, with greater variation in the type of answers. In this case, however, the estimated effect size of the difference was small $[r=-0.165(-0.28 ;-0.04)]$.

Intensity of Components per Dimension. When comparing how intensely each of the distinct phenomenological dimensions of the scale was recalled, significant differences were found between the groups (see Table 2).

In the evocation of the ARs, individuals without MDD indicated greater intensity in recalling the components of the dimensions: Valence, Sensoriality, Clarity and Intersubjectivity. The differences in the intensity of the recollection were highly significant for the dimension Valence [median group with $\mathrm{MDD}=14$; IR $=$ 12 vs. median group without $\mathrm{MDD}=22 ; \mathrm{IR}=6$; $p<.001 ; r=-0.396(-0.51 ;-0.28)]$.

Total Intensity and Quantity of Components according to the Presence of Previous Depressive Episodes. Considering Bonferroni's correction $(\alpha<0.0008)$, no statistically significant differences were found in the main EERAS scores between the subgroup of individuals with MDD and antecedents of depressive symptoms $(n=54)$ when compared to the subgroup of individuals with MDD without these antecedents $(n=40)$, in terms of the total quantity [median MDD group with antecedents $=18.5 ; \mathrm{IR}=6 \mathrm{vs}$. median MDD group without antecedents $=20 ; \mathrm{IR}=7.5 ; p=$ $.044 ; r=-0.120(-0.32 ; 0.08)]$ as well as the total intensity of the components [median MDD group with antecedents $=104 ; \mathrm{IR}=20.5$ vs. median MDD group without antecedents $=113$; $\mathrm{IR}=16.75 ; p=.018 ; r=-0.141(-0.34 ;-0.06)] \mathrm{re-}$ called.

Total Intensity and Quantity of Components according to Presence of Psychopharmacological Treatment. No statistically significant differences were found between the subgroup of individuals with MDD under psychopharmacological treatment $(n=61)$ and the subgroup of individuals with MDD under no psychopharmacological treatment $(n=33)$ in terms of the main EERAS scores for the total quantity (median MDD group under treatment $=20 ; \mathrm{IR}=7.5 \mathrm{vs}$. median MDD group without treatment $=19$; $\mathrm{IR}=6 ; p=.153)$ and for the total intensity of the components recalled (median MDD group under treatment $=111 ; \mathrm{IR}=18 \mathrm{vs}$. median MDD group without treatment $=105 ; \mathrm{IR}=20 ; p=.135$ ).

Total Intensity and Quantity of Components according to Severity of Depressive Symptoms. No statistically significant differences were found among the three subgroups of individuals with MDD based on the severity of the symptoms (see Table 1) in the main EERAS scores. The $p$-value of the Kruskal-Wallis test was 0.245 for the total quantity of components and 0.224 for the total intensity of the components.

\section{Discussion}

The primary objective in this study was to assess the phenomenological profiles in the recall of significant ARs according to the presence or absence of MDD. The secondary objective was to assess the EERAS performance in the group with MDD according to the presence of previous depressive episodes, psychopharmacological treatment and severity of the symptoms. The results found support the primary research hypothesis that individuals with MDD recall the 
phenomenological components of their ARs to a lesser extent and intensity when compared to the control group. Nevertheless, no statistical differences were found in the group of individuals with MDD when the analysis was repeated according to the three clinical variables assessed.

When the scores were compared between the groups with and without MDD for each phenomenological dimension, significant differences were found in the dimensions Visual Imagery, Valence, Sensoriality, Clarity and Intersubjectivity only. On the one hand, the group with MDD evoked a lesser amount of components related to the visual dimension of the recollection but, nevertheless, did not differ from the control group in how intensely these details were recalled. It could be considered that, as individuals with MDD access the visual components of their recollection, how intensely they recall these details is not significantly influenced. In accordance with Greenberg and Knowlton (2014), visual imagery plays a fundamental role in ARs and in cognitive functioning in general, which is why preserving the evocative quality would offer considerable adaptive benefits. On the other hand, what the sensory components are concerned (flavors, smells, sounds and tactile sensations), the group with MDD evoked the components in this dimension less intensely. In line with experience-centered approaches (Bessell et al., 2008; Holmes \& Mathews, 2010; Williams, 2010), sensory and affective processing are relevant functions in the emergence of memory phenomena. In future studies, the possibility that individuals with MDD indicate lesser intensity for these components could be assessed, as the multimodal information recall has been affected in this population. Different studies sustain that a generalized processing modality is characteristic of MDD patients (Sumner et al., 2010; Watkins, Moberly, \& Moulds, 2008; Watkins \& Teasdale, 2004). It could be considered that the group with depression displayed less intensity in the recall of sensory components as an emotional avoidance strategy (Dinis et al., 2015; Williams et al., 2007).

In addition, concerning both the quantity and intensity of the components in the Clarity dimension, the group with MDD showed significantly lower scores. That is in line with studies that argue that, the more specific the representation process, the larger the amount of details accessible in an experience (Watkins et al., 2008; Werner-Seidler \& Moulds, 2011b). Similarly, in the Intersubjectivity dimension, the clinical group indicated a lesser amount of components and a lower level of intensity than in the control group. Among other purposes, the ARs have been linked with socialization goals (Bluck et al., 2005; Harris, Rasmussen, \& Berntsen, 2013). The fact that the participants with MDD recalled the intersubjective aspects of their ARs to a lesser extent is in line with the social problems characteristic of depression cases (Bluck et al., 2005; Conway, 2005; Michalak \& Lam, 2002).

On the other hand and differently from previous studies (King et al., 2010, MacQueen et al., 2002), no significant differences were found in the memory performance of individuals with MDD according to the presence of pre-vious depressive symptoms. Nevertheless, this difference could relate to the fact that, in this study, this variable was registered in the dichotomous form. Knowing the exact number of previous episodes would have enriched the analyses. Similarly, the variable psychopharmacological treatment was not significant either in the memory performance assessed through the EERAS. As discussed in the introduction, the type of effect the psychotropic drugs provoke in AM tasks are a source of debate (Brittlebank et al., 1993; Zoladz et al., 2008). For the sake of future studies, it would be interesting to register this variable according to the type of drug and not only according to its presence or absence. Finally and in line with other studies (Lemogne et al., 2006; Watkins, Teasdale, \& Williams, 2000), no significant differences have been found either according to the severity of the MDD patients' symptoms. Although this may seem to go against intuition and in line with the literature, once MDD has developed, the changes in the cognitive processing of AM would happen independently of the clinical severity of the condition (King et al., 2010).

This study comes with a series of limitations. First, for operative reasons, the sampling 
design was non-probabilistic. This characteristic limits the range of the conclusions to the groups that accepted to participate in the research. Nevertheless, it does not limit the reliability and validity of the results found in this group. On the other hand, concerning the same research object, multiple suspicions exist regarding how exact AM operates. In line with current research, however (Bergouignan et al., 2008; Montebarocci et al., 2014), this study did not intend to assess the veracity of the contents in the ARs, but the phenomenological profiles of memory evaluated using the EERAS. And, in fact, more than the content veracity, the processing modalities of the recall experience are associated with the cognitive biases of MDD patients, and certainly with the associated mental impact (Watkins \& Teasdale, 2004). Finally, in view of the observational study, certain confounding variables could not be controlled, nor could the bias associated with this type of research be eliminated. The replicability of this study through probabilistic sampling and the control of the analyses using other relevant clinical variables would be necessary to generalize the collected information to the general population. Despite the research limitations, the results reached can be highly useful in further research on the theme.

In line with the Mindfulness (Williams, 2010) and Cognitive Imagery (Holmes \& Mathews, 2010) models, it is considered that working to enhance the specifications of those phenomenological dimensions in the recall of significant ARs that are most affected will offer significant therapeutic benefits in MDD patients (Williams et al., 2000). Affectivity, memory and identity join in constituting past and present experiences and in the elaboration of people's future projections (Janssen et al., 2015; Mullally \& Maguire, 2013). Further deepening the intricate relations among these cognitive functions can offer highly useful information in the clinical and theoretical context of AM.

\section{References}

American Psychiatric Association. (2000). Diagnostic and statistical manual of mental disorders ( $4^{\text {th }}$ ed.). Washington, DC: Author.
Beck, A. T., Steer, R. A., Ball, R., \& Ranieri, W. (1996). Comparison of Beck Depression Inventories-IA and -II in psychiatric outpatients. Journal of Personality Assessment, 67, 588-597.

Bergouignan, L., Lemogne, C., Foucher, A., Longin, E., Vistoli, D., Allilaire, J.-F., \& Fossati, P. (2008). Field perspective deficit for positive memories characterizes autobiographical memory in euthymic depressed patients. Behaviour Research and Therapy, 46(3), 322-333.

Bessell, A. L., Watkins, E., \& Williams, W. H. (2008). Depressive rumination reduces specificity of autobiographical memory recall in acquired brain injury. Journal of the International Neuropsychological Society: JINS, 14(1), 63-70.

Bluck, S., Alea, N., \& Habermas, T. (2005). A tale of three functions: The self- report uses of autobiographical memory. Social Cognition, 23(1), 91-117.

Bonicatto, S., Dew, M. A., \& Soria, J. (1998). Analysis of the psychometric properties of the Spanish version of the Beck Depression Inventory in Argentina. Psychiatric Research, 79, 277-285.

Brittlebank, A. D., Scott, J., Williams, J. M. G., \& Ferrier, I. N. (1993). Autobiographical memory in depression: State or trait marker? British Journal of Psychiatry, 162, 118-121.

Camacho Sandoval, J. (2008). Tamaño de Muestra en Estudios Clínicos [Sample Size in Clinical Studies]. Acta Médica Costarricense, 50(1), 20-21.

Carracedo-Martínez, E., \& Figueiras, A. (2006). Tratamiento estadístico de la falta de respuesta en estudios epidemiológicos transversales. Salud Pública de México, 48(4), 341-347. doi:10.1590/ S0036-36342006000400009

Conway, M. A. (2005). Memory and the self. Journal of Memory and Language, 53(4), 594-628. doi:10.1016/j.jml.2005.08.005

Cortina, J. M. (1993). What is coefficient alpha? An examination of theory and applications. Journal of Applied Psychology, 78, 98-104.

Crawley, R. (2014). Trait mindfulness and autobiographical memory specificity. Cognitive Processing, 79-86. doi:10.1007/s10339-014-0631-3

Cronbach, L. J. (1951). Coefficient alpha and the internal structure of tests. Psychometrika, 16(3), 297-234. doi:10.1007/BF02310555. ISSN 00333123 
Dinis, A., Carvalho, S., Gouveia, J. P., \& Estanqueiro, C. (2015). Shame memories and depression symptoms. The Role of Cognitive Fusion and Experiential Avoidance, 63-86.

Greenberg, D. L., \& Knowlton, B. J. (2014). The role of visual imagery in autobiographical memory. Memory \& Cognition, 42(6), 922-934. doi:10.3758/s13421-014-0402-5

Harris, C. B., Rasmussen, A. S., \& Berntsen, D. (2013, November). The functions of autobiographical memory: An integrative approach. Memory (Hove, England), 37-41.

Hernández Sampieri, F., Fernández Collado, C., \& Baptista, L. P. (2006). Metodología de la Investigación [Research Methodology]. Buenos Aires: Belgrano.

Holmes, E. A, \& Mathews, A. (2010). Mental imagery in emotion and emotional disorders. Clinical Psychology Review, 30(3), 349-362. doi:10.1016/j.cpr.2010.01.001

Janssen, S. M. J., Kristo, G., Rouw, R., \& Murre, J. M. J. (2015). The relation between verbal and visuospatial memory and autobiographical memory. Consciousness and Cognition, 31, 1223. doi:10.1016/j.concog.2014.10.001

King, M. J., MacDougall, A. G., Ferris, S. M., Levine, B., MacQueen, G. M., \& McKinnon, M. C. (2010). A review of factors that moderate autobiographical memory performance in patients with major depressive disorder. Journal of Clinical and Experimental Neuropsychology, 32(10), 1122-1144. doi:10.1080/13803391003781874

Kuyken, W., \& Dalgleish, T. (2011). Overgeneral autobiographical memory in adolescents at risk for depression. Memory (Hove, England), 19(3), 241-250. doi:10.1080/09658211.2011.554421

Kuyken, W., \& Howell, R. (2006). Facets of autobiographical memory in adolescents with major depressive disorder and never depressed controls. Cognition \& Emotion, 20(3-4), 466-487. doi:10.1080/02699930500342639

Lasa, L., Ayuso-Mateos, J. L., Vázquez-Barquero, J. L., Díez-Manrique, F. J., \& Dowrick, C. F. (2000). Use of the Beck Depression Inventory to screen for depression in the general population: preliminary analysis. Journal of Affective Disorders, 57, 261-265.

Leiderman, E. A., Vázquez, G. H., Lolich, M., \& Baldessarini, R. (2012). Depression: Pointprevalence and sociodemographic correlates in a Buenos Aires community sample. Journal of Affective Disorders, 136(3), 1154-1158.
Lemogne, C., Piolino, P., Friszer, S., Claret, A., Girault, N., Jouvent, R., ...Fossati, P. (2006). Episodic autobiographical memory in depression: Specificity, autonoetic consciousness, and self-perspective. Consciousness and Cognition, 15(2), 258-268.

Lenth, R. V. (2006-2009). Java Applets for power and sample size [Computer software].

Liu, X., Li, L., Xiao, J., Yang, J., \& Jiang, X. (2013). Abnormalities of autobiographical memory of patients with depressive disorders: A meta-analysis. Psychology and Psychotherapy: Theory, Research and Practice, 86(4), 353-373.

Lolich, M., \& Azzollini, S. (2012). Instrumentos de evaluación de la memoria autobiográfica y sus dimensiones fenomenológicas [Assessment tools of autobiographical memory and its phenomenological dimensions]. Acta Psiquiatrica y Psicológica de América Latina, 4(58), 256-269.

Lolich, M., \& Azzollini (2016) Escala de evaluación de recuerdos autobiográficos significativos: diseño y validación. [Evaluation of significant autobiographical memories scale: design and validation]. Vertex (27), 405-419.

Luchetti, M., \& Sutin, A. R. (2015, May). Measuring the phenomenology of autobiographical memory: A short form of the Memory Experiences Questionnaire. Memory, 1-11. doi:10.1080/0965 8211.2015.1031679

MacQueen, G. M., Galway, T. M., Hay, J., Young, L. T., \& Joffe, R. T. (2002). Recollection memory deficits in patients with major depressive disorder predicted by past depressions but not current mood state or treatment status. Psychological Medicine, 32(2), 251-258.

Magila, M. C., \& Xavier, G. F. (2000). Interação entre sistemas e processos de memória em humanos [Interaction between memory systems and processes in humans]. Temas em Psicologia, 8(2), 143-154. Retrieved from http://pepsic.bvsalud. org/scielo.php?script=sci_arttext\&pid=S1413389X2000000200004\&lng=pt\&tlng=pt

Michalak, E., \& Lam, R. (2002). Breaking the myths: new treatment approaches for chronic depression. Canadian Journal of Psychiatry, 47(7).

Montebarocci, O., Luchetti, M., \& Sutin, A. R. (2014). Age, memory type, and the phenomenology of autobiographical memory: Findings from an Italian sample. Memory (Hove, England), 22(3), 295-306. doi:10.1080/09658211.2013.786093 
Mullally, S. L., \& Maguire, E. A. (2013). Memory, imagination, and predicting the future: A common brain mechanism? The Neuroscientist: A Review Journal Bringing Neurobiology, Neurology and Psychiatry, 20(3), 220-234. doi:10.1177/1073858413495091

Park, R. J., Goodyer, I. M., \& Teasdale, J. D. (2002). Categoric overgeneral autobiographical memory in adolescents with major depressive disorder. Psychological Medicine, 32(2), 267-276. Retrieved from http://www.ncbi.nlm.nih.gov/ pubmed/11866322

Rosenthal, R.(1991). Meta- analytic procedures for social research $\left(2^{\text {nd }}\right.$ ed.). Newbury Park, CA: Sage.

Rottenberg, J., Joormann, J., Brozovich, F., \& Gotlib, I. H. (2005). Emotional intensity of idiographic sad memories in depression predicts symptom levels 1 year later. Emotion (Washington, D.C.), 5(2), 238-242. doi:10.1037/1528-3542.5.2.238

Sumner, J. A., Griffith, J. W., \& Mineka, S. (2010). Overgeneral autobiographical memory as a predictor of the course of depression: A meta-analysis. Behaviour Research and Therapy, 48(7), 614-625. doi:10.1016/j.brat.2010.03.013

Sumner, J. A., Mineka, S., Zinbarg, R. E., Craske, M. G., Vrshek-Schallhorn, S., \& Epstein, A. (2014). Examining the long-term stability of overgeneral autobiographical memory. Memory (Hove, England), 22(3), 163-170. doi:10.1080/0965821 1.2013 .774021

Sutin, A. R., \& Robins, R. W. (2007). Phenomenology of autobiographical memories: The memory experiences questionnaire. Memory (Hove, England), 15(4), 390-411.

Sutin, A. R., \& Robins, R. W. (2010). Correlates and phenomenology of first and third person memories. Memory (Hove, England), 18(6), 625-637. doi:10.1080/09658211.2010.497765

Tanis, K. Q., Newton, S. S., \& Duman, R. S. (2007). Targeting neurotrophic/growth factor expression and signaling for antidepressant drug development. CNS and Neurological Disorders-Drug Targets, 6(2), 151-160.

Téllez, A., García, C. H., \& Corral-Verdugo, V. (2015). Effect size, confidence intervals and statistical power in psychological research. $P$ sychology in Russia: State of the Art, 8(3), 27-46. http://doi.org/10.11621/pir.2015.0303

Tulving, E. (2002). Episodic Memory: From Mind to Brain. Annual Review of Psychology, 53, 1-25.
Watkins, E., Moberly, N. J., \& Moulds, M. L. (2008). Processing mode causally influences emotional reactivity: distinct effects of abstract versus concrete construal on emotional response. Emotion (Washington, D.C.), 8(3), 364-378. doi:10.1037/1528-3542.8.3.364

Watkins, E., \& Teasdale, J. D. (2004). Adaptive and maladaptive self-focus in depression. Journal of Affective Disorders, 82(1), 1-8. doi:10.1016/j. jad.2003.10.006

Watkins, E., Teasdale, J. D., \& Williams, R. M. (2000). Decentring and distraction reduce overgeneral autobiographical memory in depression. Psychological Medicine, 30(4), 911-920.

Werner-Seidler, A., \& Moulds, M. L. (2011a). Autobiographical memory characteristics in depression vulnerability: Formerly depressed individuals recall less vivid positive memories. Cognition \& Emotion, 25(6), 1087-1103. doi:1 $0.1080 / 02699931.2010 .531007$

Werner-Seidler, A., \& Moulds, M. L. (2011b). Mood repair and processing mode in depression. Emotion, 12(3), 470-478.

Williams, J. M. G. (1995). The Autobiographical Memory Test. Bangor, ME: University of Wales.

Williams, J. M. G. (2010). Mindfulness and psychological process. Emotion (Washington, D.C.), 10(1), 1-7. doi:10.1037/a0018360

Williams, J. M. G., Barnhofer, T., Crane, C., Herman, D., Raes, F., Watkins, E., \& Dalgleish, T. (2007). Autobiographical memory specificity and emotional disorder. Psychological Bulletin, 133(1), 122-148. doi:10.1037/0033-2909.133.1.122

Williams, J. M. G., Teasdale, J. D., Segal, Z. V., \& Soulsby, J. (2000). Mindfulness-based cognitive therapy reduces overgeneral autobiographical memory in formerly depressed patients. Journal of Abnormal Psychology, 109(1), 150-155. doi:10.1037//0021-843X.109.1.150

Zoladz, P. R., Park, C. R., Muñoz, C., Fleshner, M., \& Diamond, D. M. (2008). Tianeptine: An antidepressant with memory-protective properties. Current Neuropharmacology, 6(4), 311-321. 